\title{
Antigas InQuietaÇÕes SOB NOvos temas
}

\author{
Mônica Junqueira de Camargo
}

O denso conteúdo desta edição ilustra o avanço que as pesquisas acadêmicas têm proporcionado ao campo da arquitetura e do urbanismo, começando com a oportuna apresentação da Profa. Dra. Maria Lucia Refinetti Martins, na qual analisa as especificidades da pesquisa nessa área de conhecimento, a partir de sua experiência como presidente da Comissão de PósGraduação da FAUUSP e como membro do Conselho Central de Pós-Graduação da USP. Nesse texto, a professora faz um balanço das pesquisas produzidas na área a partir dos trabalhos editados, para o qual coordenou um raro esforço de classificação, resultando todo um inédito panorama da configuração do conjunto de trabalhos do último triênio. A partir dos dados obtidos é possível avaliar o estado da pesquisa em arquitetura, refletir sobre sua trajetória e debater sobre os rumos a seguir.

Os dez artigos aprovados para esta edição referem-se a pesquisas inéditas, que avançam sobre textos ou projetos já explorados anteriormente; entretanto, são novas leituras que estabelecem novas relações na área da arquitetura, ampliando, consideravelmente, o conhecimento do campo disciplinar e reforçando a inesgotabilidade dos temas. Dois temas foram privilegiados pelas pesquisas apresentadas: a complexidade das cidades contemporâneas, do ponto de vista da infra-estrutura, da paisagem e da habitação e as questões conceituais no âmbito da estética e da filosofia da arte e da arquitetura, embora as investigações da área da técnica sempre confirmem presença, que nesta edição são discutidas em dois artigos. Os quatro primeiros artigos contribuem para o questionamento da produção do ambiente urbano contemporâneo, trazendo reflexões que podem contribuir para o avanço das discussões sobre as cidades e a melhoria do espaço urbano.

A análise de Marcelo Sacenco Asquino sobre os desafios contemporâneos da metrópole paulistana, intitulada "Governança metropolitana e infra-estrutura em São Paulo: O desafio de conciliar interesses regionais e impacto local", é muito oportuna diante da complexidade de intervir-se nessa cidade, tendo em vista a amplitude de sua escala regional. A partir de uma retrospectiva histórica que localiza alguns pontos decisivos de sua evolução urbana, e com base na problemática de alguns projetos atuais, como a ampliação da calha do rio Tietê e o Rodoanel Trecho Sul, o autor traz à discussão os embates do sistema de planejamento metropolitano de 1970, com as novas condições impostas pelos processos de licenciamento ambiental, concluindo com a necessidade de uma revisão e atualização do modelo metropolitano em vigor, segundo novas premissas.

Sob o título de "O new urbanism e sua influência no Brasil: O caso da 'Cidade Universitária Pedra Branca' em Palhoça, SC", Fernando Pinto Ribeiro analisa esse modelo americano surgido na década de 1980 em reação ao fenômeno da suburbanização característico do pós-segunda guerra, discutindo sua apropriação pelo empreendimento, Pedra Branca, no município de Palhoça, SC. Com base em princípios urbanísticos que privilegiam as cidades menores e densas, com zoneamento multifuncional, e onde a mobilidade minimize o uso do automóvel, está se estruturando um loteamento que integra um importante processo de reconfiguração urbana da região metropolitana de Florianópolis. Entretanto, a análise de Ribeiro revela que a simples implantação de tais princípios não garantira às experiências americanas a pretendida diversidade social e arquitetônica, e que essas se aproximam mais da realidade de um condomínio fechado, malgrado o disfarce de abertura, uma vez que esses loteamentos não são murados, do que uma nova sociabilidade urbana. Também sua adaptação à realidade brasileira se configura como um espaço da segregação.

Leandro Medrano, no artigo "Habitação coletiva e cidade. Invenção sem ruptura", questiona a produção arquitetônica contemporânea em sua incapacidade de criar vida urbana, contestando a inadequação de seus pressupostos teóricos. A partir da análise de duas experiências habitacionais muito distintas entre si, mas exemplares, segundo a avaliação do autor, são apontadas as estratégias dos respectivos arquitetos, de qualificação e desenvolvimento do ambiente urbano. A primeira em Barcelona, em meados dos anos 50, Vivendas del Congresso Eucarístico, dos arquitetos Carles Marqués i Maristany, Antoni Pineda i Gualba e Josep Soteras i Mauri, cujo desenho urbano muito dinâmico teve como base estrutural distintas tipologias. A segunda é um projeto, do início dos anos 80, de Alvaro Siza para Doedijnstraat, Holanda, que tem como premissa a visão crítica e dialética da cultura e história locais. 
A persistente investigação de Vladimir Bartalini sobre a conformação da paisagem paulistana - brinda-nos no artigo "Palcos e bastidores" (ainda sobre córregos ocultos), com uma análise muito precisa das rotas dos córregos: do Sapateiro, que conforma o lago do Parque do Ibirapuera e os da Aclimação, Pedra Azul, que passa a chamar-se Cambuci, a abastecerem o lago do parque de mesmo nome. Bartalini apresenta uma incrível proposta de unir esses dois importantes espaços de lazer, distantes entre si quatro quilômetros, por meio dos percursos desses córregos, abrindo alternativas para pedestres e ciclistas, mas também oportunidades para vivificar a memória desses sítios.

Os quatro artigos seguintes tomam a senda do campo teórico e conceitual, recuperando idéias exploradas por consagrados teóricos para a compreensão da problemática contemporânea.

Rafael Urano Frajndlich, em seu artigo "Pórticos, letreiros, lareiras. Le Corbusier e Robert Venturi, sobre simbolismo e velocidade no modernismo", investiga a leitura de Robert Venturi sobre as obras de Le Corbusier. Atento não só aos textos, mas ao material gráfico que os acompanham, Rafael identifica as considerações do mestre franco-suíço entre arquitetura e comunicação, como a retórica, a alusão, a memória dos centros históricos e dos interiores decorados, que foram amplamente explorados pelos discursos pós-modernistas, especialmente o de Robert Venturi, seu astuto interlocutor, e apontam parte do dilema da tradição no cerne da modernidade.

Em "O conceito de aura de Walter Benjamin e a indústria cultural" Bráulio Santos Rabelo de Araújo apresenta o confronto de idéias de dois textos consagrados: A obra de arte na era da reprodutibilidade técnica, de 1935, de Walter Benjamin, e A indústria cultural: O esclarecimento como mistificação das massas, de Theodor Adorno e Max Horkheimer, de 1947, comprovando a importância e atualidade das idéias debatidas. A partir da observação das manifestações artísticas necessariamente reprodutíveis como cinema, música e livro, o autor conclui que os elementos centrais da aura (autenticidade e unicidade) nas técnicas analisadas por Benjamin, não foram superados, mas, ao contrário, adaptaram-se às mudanças técnicas decorrentes da industrialização e levanta questões interessantes para a reflexão a respeito dos impactos da
Internet e das tecnologias digitais sobre a produção cultural contemporânea.

A partir da observação do conjunto residencial projetado por Zaha Hadid em Viena, Igor Guatelli desenvolve uma investigação sobre as relações do objeto construído e as condições em que se insere.

Especulando sobre a possibilidade de a arquitetura ser pensada como um rastro, daí o título do artigo, "Indeléveis rastros", Guatelli busca entender o objeto construído, para além dele próprio, ao mesmo tempo valorizando sua presença e questionando sua autosuficiência. O conjunto de três blocos de habitações estudantis localiza-se sobre uma estação de metrô e um viaduto, projetado pelo arquiteto vienense Otto Wagner, de um ramal férreo desativado, hoje transformado em uma ciclovia. Mais preocupado com as articulações que a arquitetura estabelece com o público e a cidade, o autor destaca a capacidade de a arquiteta saber trabalhar a complexa articulação entre o novo e as preexistências, de modo que sua arquitetura, não apenas respeita, mas se fortalece com a condição urbana que Ihe é dada.

Fellipe de Andrade Abreu e Lima em "Ética e estética nas arte, arquitetura e urbanismo contemporâneos - Uma crítica realista" lança-se ao desafio de examinar o conflito atual no campo das artes, principalmente da arquitetura, no sentido de identificar a dimensão social dessa produção. Para tanto, a autor traça um longo percurso do renascimento à modernidade, valendo-se de autores e conceitos muito distintos que exigirá do leitor certo empenho para acompanhar seu raciocínio.

As investigações recentes no âmbito da tecnologia são apresentadas nos dois artigos seguintes. Sob o título de "O seringueiro amazônico e a sustentabilidade de sua habitação," Valdeci Candido de Lima analisa a cultura da exploração da borracha no estado do Acre desde a chegada dos primeiros seringueiros, na época áurea dessa atividade econômica até meados do século 20. Analisando o modo de vida do seringueiro, a autora identifica, na arquitetura vernácula que se produz naquela região, uma cultura construtiva que se encaixa nos atuais conceitos de sustentabilidade. Ainda que construídas de modo empírico, as moradias dos seringueiros apresentam bons índices de adequação ao ambiente em que se inserem, fazem o uso parcimonioso 
dos materiais nativos e têm um bom padrão de conforto, tanto térmico como de iluminação, sugerindo que a sustentabilidade também pode ser uma questão de intuição.

Em "A influência das reflexões internas como contribuição da iluminação natural no ambiente construído", Raphaela Walger da Fonseca apresenta o resultado de suas investigações sobre a influência das reflexões internas na iluminação natural do ambiente construído. Discutindo elementos que interferem nos valores e na distribuição da luz, como a geometria do espaço interno, as propriedades das superfícies, bem como a área, a posição e a distribuição das aberturas, influenciam nos valores e na distribuição atribuídos à iluminação refletida interna. A partir de métodos gráficos e analíticos criados durante a pesquisa, foi possível a comparação entre geometrias e entre conceitos de iluminação natural propostos, e a verificação da qualidade e da eficiência do projeto de iluminação em relação ao aproveitamento das reflexões da luz. Trata-se da criação de recursos que poderão orientar o arquiteto em seu processo de projeto.

As seções Eventos e Resenhas comprovam a vitalidade dos convênios e parcerias do curso de Arquitetura da FAUUSP, que nesta edição registra, com satisfação, dois prêmios de destaque para a história da FAU. O primeiro é o título de professor emérito da FAUUSP ao arquiteto Paulo Mendes da Rocha, pelo reconhecimento de sua contribuição às atividades acadêmicas, cuja saudação do Prof. Dr. Hugo Segawa destaca a qualidade de sua trajetória e o reconhecimento internacional que tem recebido. 0 homenageado, por sua vez, retoma sua formação profissional, apontando a importância de alguns professores e trazendo a público sua reflexão, o papel da arquitetura na sociedade contemporânea.

O segundo é um prêmio nacional - Marta Rossetti Batista, organizado pelo IEB-USP para a melhor pesquisa inédita sobre arte e arquitetura escrita no Brasil, que, em 2009, foi atribuído ao doutorado de Rodrigo Almeida Bastos, desenvolvido na FAUUSP sob a orientação do Prof. Dr. Mario Henrique D’Agostino A maravilhosa fábrica de virtudes: O decoro na arquitetura religiosa de Vila Rica, Minas Gerais (17111822) é uma leitura inédita do patrimônio arquitetônico brasileiro do século 18, por meio dos preceitos e das doutrinas artísticas que fundamentavam a prática arquitetônica daquela época.

Os relatos dos laboratórios de pesquisa apresentam algumas atividades com caráter de extensão, importante aspecto do ensino universitário que nem sempre tem recebido o devido destaque. São propostas que buscam integrar as investigações acadêmicas a um público mais amplo, tanto especializado como da comunidade, também predispostos a discutir sobre cidade. Em "aprender sobre a cidade ou aprender com a cidade? Projeto arte no Heliópolis (2009)", Euler Sandeville Jr. traz a experiência de sua disciplina optativa da graduação - "Arte e Projeto da Paisagem", estabelecendo um processo coletivo de concepção e organização, que envolveu alunos, moradores e artistas independentes. A partir da compreensão de paisagem como uma experiência partilhada e socialmente construída, o projeto se funda na proposição da espiral da sensibilidade e do conhecimento e na proposição de um programa de educação-pesquisa-aprendizagem em ação.

Considerando a relevância dos laboratórios na formação discente e na relação com a comunidade, a Comissão Editorial decidiu abrir espaço para as outras instituições relatarem suas experiências, que pretendemos acolher a partir da próxima edição.

O relato de Manoel Rodrigues Alves sobre o seminário "Cidade(s): Novas Espacialidades e Territorialidades", apresenta, além do quadro recente das pesquisas sobre o urbanismo, as formas emergentes de urbanidade em suas dimensões socioculturais, correlacionando suas especificidades territoriais, ambientais, sociais e públicas, seus processos de transformação e suas permanências, seus elementos estruturantes e suas linhas de força, enquanto as discussões do "III Colóquio Internacional Sobre Comércio e Cidade: Uma Relação de Origem" são relatadas pela pela Profa. Dra. Heliana Comin Vargas.

As seis resenhas são reveladoras do grau de inquietação e de amadurecimento das reflexões no campo da arquitetura, começando pela inédita tradução para o português de um tratado fundamental como "Os quatro livros de arquitetura", de Andrea Palladio, de 1570, que Andrea Buchidid Loewen analisa em detalhes. Na seqüência, "Além das formas. Introdução ao pensamento contemporâneo no design, nas artes e na arquitetura", por Milena Szafir; "Lina por escrito: Textos escolhidos de Lina Bo Bardi 1943-1991"; "Ideologia da casa própria... sem casa própria. O programa de arrendamento residencial na cidade de João PessoaPB", por Pedro Fiori Arantes; "The political economy of public space", por Sergio Abrahão; e "Canteiro experimental", que tive o prazer de comentar.

Boa leitura.

Mônica Junqueira de Camargo Editora-chefe 